\title{
Behavioural loyalty towards store brands
}

\author{
J.M. Labeaga ${ }^{\mathrm{a}, \mathrm{d}}$, N. Lado ${ }^{\mathrm{b}}$, M. Martos ${ }^{\mathrm{c}, *} \equiv$ \\ ${ }^{a}$ Dpto. Análisis Económico II, Universidad Nacional de Educación a Distancia (UNED), \\ Office 2.26. Paseo Senda del Rey 11. 28040 Madrid, Spain \\ ${ }^{\mathrm{b}}$ Dpto. Economía de la Empresa, Universidad Carlos III de Madrid, Calle Madrid 126, 28903 Getafe (Madrid), Spain \\ ${ }^{\mathrm{c}}$ Dpto. Administración y Economía de la Empresa, Universidad de Salamanca, Campus Miguel de Unamuno, 37007 Salamanca, Spain \\ ${ }^{\mathrm{d}}$ FEDEA, Calle Jorge Juan 46, 28001 Madrid, Spain
}

\begin{abstract}
This paper applies a consumer brand choice model to measure store brand (SB) loyalty. The aim of this paper is to examine whether SB loyalty is different across categories, and we focus on risk perception as an explanatory variable. The model is estimated using ACNielsen Spanish household scanner panel data on two laundry detergent categories over a 2 year period for more than 1107 households. Loyalty, price, socio demographics and shopping behaviour variables are included. The discrete choice model formulation is the logit model.
\end{abstract}

Keywords: Store brands; National brands; Brand loyalty; Logit model; Household scanner panel

\section{Introduction}

Store brands (SBs), also known as private labels or retail brands, have enjoyed increased success in recent years. This has been especially noticeable in the case of non-durable consumer goods, where SBs continue to steadily increase their share of the global market. Moreover, Europe shows its traditional dominance in terms of market share of SBs. Spain is among the top five markets (ACNielsen, 2005) where the market share of SBs reached $26 \%$ in 2005, and according to the ACNielsen forecast, sales will increase at double the rate of national brands (NBs) in 2006. Laundry detergents and non-food groceries is one of the categories in which SBs have had more success in Spain, enjoying a market share approaching 30\%.

The study of Erdem et al. (2004) analysed how consumer attitudes toward risk, quality, and price play an important role in consumers' SB choice. Considering these variables, the authors studied the differences in relative success of SBs across some European countries, including Spain and the United States. They concluded that the differential success of SBs in Europe with respect to the US

\footnotetext{
*Corresponding author. Fax: + 34923294715 .

E mail address: mmartos@usal.es (M. Martos).
}

may be partially explained by the higher brand equity of the European SBs.

SBs in the Spanish market have less quality uncertainty associated with them, and they deliver more consistent positioning and quality levels over time than do the SBs in the US market. Another conclusion of the Erdem et al. (2004) study is that the consumers in Spain are more price sensitive than quality sensitive compared to consumers in the US. This is one of the explanations for the success of SBs in Spain.

On the other hand, others recent studies focusing on the comparison of SBs and NBs from the consumer perception point of view conclude that SBs have lower brand equity than NBs. The study developed by Wulf et al. (2005) for the European market (Belgium) concluded that even if SBs can offer the same quality as NBs, SBs create no perceived positive difference and lack significant brand equity. Confirming the common belief that SBs products can offer the same quality level as NBs, the blind test developed by Wulf et al. (2005) showed that SBs ranked higher than NBs in quality perception and preference. However, consumers ranked SBs higher in a blind test than in a non-blind test. Their interpretation of this result is that SBs have no brand equity. Similar conclusions were reached in the study of Juhl et al. (2006) of the Denmark market. They found that 
SBs are not the preferred brands, and nor do SBs predominate in the minds of costumers in any of the analysed categories.

However, as Erdem et al. (2004) explained, the success of SBs in Europe is based on their relative perceived quality and brand equity. Steenkamp and Dekimpe (1997) found that the power of SBs vary dramatically across product categories in the Dutch market. In categories where SBs do well in terms of market share, it is because there is a base of loyal SB consumers or conquering power (a base of switching consumers) or both. These results ought to lead retail chains to improve their quality in order to raise the image of the chain and to encourage consumer loyalty. This situation occurs in the Spanish case where SBs are positioned by retailers with quality levels similar to those of NBs but as lower prices (Medina et al., 2004).

Brand equity is a complex concept that can be measured using different approaches (Keller, 2003). For the SBs case in a European context, it seems that when the study focus is on brand quality perceptions as a foundation of brand equity, the conclusion is that SBs have brand equity. Conversely, when the studies analyse brand equity considering awareness and differentiation power, the conclusion is the opposite. We claim that more research incorporating other important foundations of brand equity for SBs is needed.

Taking into account the increasing penetration of SBs, especially in Spain, and the contradictory results concerning $\mathrm{SB}$ equity in the European context, our research purpose is to study the brand value of SBs in Spain. We focus our attention on one of the principal brand equity bases: brand loyalty (Aaker, 1991). Our intention is to answer the following question: Can we still continue to claim that NBs receive a higher level of loyalty than SBs in Spain?

According to Dhar and Hoch (1997) and Ailawadi and Keller (2004), SB success is more category driven than consumer driven. SBs seem to enjoy a higher share in large, less-promoted categories with high market concentration when price gaps between NBs and SBs are large.

Erdem et al. (2004) have studied how differences in perceived risk across countries can explain the difference in SB performance. They modelled perceived risk as the consistency in quality levels measured by the variance of consumer quality belief. The literature on cross-category differences in SB shares (Batra and Sinha, 2000), suggests that differences are likely to be greater in categories with low perceived consumer risk (lower consequences of making a mistake in a purchase, lower quality variability and when the category has lower "experience" than "search" characteristics). Other category-related aspects that may underlie risk perception differences, such as financial and material risk associated with a product category, have not received enough attention.

As a consequence, our second research question is: Which aspects of risk associated with a specific product category can explain SB loyalty differences across categories?
In order to analyse SB loyalty versus NB loyalty, as well as to contrast household brand choice behaviour in different categories, we estimate a binomial logit model. More specifically, we apply our SB loyalty analysis to the comparison of two detergent laundry categories in the Spanish market.

The rest of the paper is organized as follows. In the next section, we review brand loyalty in the discrete-choice model literature and we propose our hypothesis. Then we describe data sources and variables. After that we set up an empirical model using the specification model described in the literature and we discuss the findings. Finally, we present conclusions and implications.

\section{Literature review and hypothesis}

Brand choice studies have devoted special attention to frequently purchased packaged goods. Understanding brand choices has been of interest to marketing managers and academics for a long time (three good examples are the special issues edited in 1999, 2002 and 2005 by the Marketing Letters Review). In the first stage, stochastic models were proposed as a framework to help understand patterns in household brand choices. However, in the second stage, researchers adopted logit and probit models derived from the theory of utility (McFadden, 1973), in order to incorporate the influence of marketing variables.

Random utility models enable researchers to incorporate the effects of a household's current choice on its future choices as a way to measure the effects of brand loyalty on brand choices. For example, it may be costly for households to search for and decide about brand choice, especially in low-priced, frequently purchased product categories. In such cases, households may routinize their brand purchases by buying the same brand repeatedly over time (Howard and Sheth, 1969). This means that the currently chosen brand has higher probability than other brands of being chosen in the future. This is a case of loyalty or inertia behaviour. In contrast, households may satiate themselves with previously chosen brands and change brands in a quest for variety (McAlister, 1982; Kim et al., 2002). In such a scenario, the currently chosen brand has a lower probability than other brands of being chosen in the future. This is a case of variety-seeking behaviour.

Researchers have accommodated past choice behaviour as an explanatory variable in random utility models by including a lagged purchase variable (Jones and Landwehr, 1988) or a variable constructed from lagged purchases. This has been done extensively in the context of the logit (Guadagni and Little, 1983; Erdem, 1996, for instance) and probit (Keane, 1997) frameworks. The general finding in this literature is that there is loyalty in low-price, frequently purchased product categories. This finding is consistent with Howard and Sheth's (1969) theory of routinized response behaviour; that is, households exhibit inertia in their brand choices over time. 
Despite many advances in marketing models, the proposal by Guadagni and Little (1983; hereafter, G\&L) still serves as a benchmark. The key variable that allows the model to accurately fit the data is the loyalty variable, which is an exponential smoothing of past purchases (behavioural loyalty, stochastic approach).

The G\&L measure of brand loyalty is able to track differences in purchase behaviour across consumers and over time, but it cannot properly distinguish between sources of variation in utility due to heterogeneity (across households) and sources of variation due to non-stationarity (within a household over time). The loyalty variable confounds two effects: state dependence (sometimes called purchase feedback) and household heterogeneity. Heterogeneity refers to differences across households in brand preference, and state dependence refers to the impact of past purchases on current preferences.

Many papers show that the G\&L loyalty variable does not capture consumer heterogeneity sufficiently well (Ortmeyer et al., 1991; Fader and Lattin, 1993). As pointed out by Lattin (1987), when using a single loyalty term we are implicitly assuming that differences across consumers and differences over time equally contribute to heterogeneity in base-level utility. If such an assumption is inappropriate, it could have a distorting effect on the choice model. To avoid this problem, other measures that split cross-sectional and longitudinal effects have been proposed. The study of Lattin and Bucklin (1989; hereafter, L\&B) is one of them and proposed a discrete-choice model that includes two measures of past-purchase behaviour: heterogeneity and state dependence to split the effects.

On the other hand, there are an important number of aspects in the behaviour of consumers, such as choice process and purchase frequency that differ across households and change across products. These variations might be partially the consequence of differences in perceived risk associated with the product purchase (Laurent and Kapferer, 1985). We expect that if there are differences in the degree of consumer perceived risk across different product categories, there will be differences in the level of loyalty. Dick and Basu (1994) proposed that, all other things being equal, the higher the involvement in a consumption category, the greater will be the likelihood of loyalty toward specific brands within that category.

\subsection{Proposed hypothesis}

The type of product category influences brand choice decision, and therefore it influences choice repetition or loyalty (Dick and Basu, 1994; Seetharaman et al., 1999; Chaudhuri and Holbrook, 2001). In this way, in lowpriced, frequently purchased product categories households may routinize their brand purchases by buying the same brand repeatedly over time (Howard and Sheth, 1969). However, does the same reasoning apply to SBs?
Corstjens and Lal (2000) assumed that the retailer can improve its profitability by introducing a SB in a qualityconscious segment because of the presence of inertia in brand switching. High-income and quality-sensitive consumers, who can be characterized by this inertia, prefer to buy the same brand they bought on the previous purchase occasion even through they might perceive other brands to provide the same price/quality benefits, because of their psychological commitment to prior choices and their desire to minimize their cost of thinking and/or loss aversion. This behaviour is rational because it helps consumers achieve satisfactory outcomes by simplifying the decision-making process and saving on the costs of making decisions. Bronnenberg and Wathieu (1996) reported that estimates of loyalty for SBs are comparable to those of NBs.

On the other hand, literature on private label attitudes (Burton et al., 1998; Garretson et al., 2002) indicates that the relationship between brand loyalty and private label attitude is negative, suggesting that consumers concerned with paying lower prices are less loyal towards specific brands and instead tend to exhibit stronger variety-seeking tendencies. Despite these attitudinal results, we expect to find loyalty behaviour towards SBs in low-priced and frequently purchased product categories.

Concerning the brand loyalty difference between product categories, we will focus our attention on risk perception as an explanatory variable. Risk perception may be determined by several factors. Some of these factors depend on the individual, while others are more likely to be determined by the characteristics of the product category. Moreover, we consider that variety seeking implies some risk assumption by the household. Various studies (for example, Richardson et al., 1996; Gónzalez et al., 2006) have shown that the risk associated with buying a SB product is significantly higher than buying a NB alternative. We claim that brand loyalty behaviour is a customer strategy for reducing risk associated with a purchase decision (Sheth and Venkatesan, 1968; Roselius, 1971). Our main assumption is that there is a direct relationship between risk perception associated with a product category and the mean brand loyalty that the brands within the category will receive. SBs are generally considered by consumers to be riskier alternatives; as a consequence, we consider that consumers who buy SBs will be more likely to repeat purchase as a way to reduce the risks of brand choice.

Perceived risk is a complex variable with different aspects, including financial, material and psychological dimensions (Assael, 1998).

With regard to financial risk, categories representing higher expenses inside the household basket of goods will imply higher relative perceived risk and consequently the household will inhibit the tendency towards variety seeking (Kahn et al., 1986). Therefore, in categories where household expenses are higher, we expect higher loyalty or inertia than in categories where household expenses are lower. The expenditure category across the sample can be used as a proxy to measure consumer financial risk. We do not know 
with certainty which components of perceived risk have higher weight: whether the financial risk involved has higher weight or other negative consequences associated with an inaccurate choice decision have higher weight. Moreover, the literature suggests that the perceived risk associated with the product purchase has two facets: perceived importance of negative consequences in cases of poor choice, and the perceived probability of making such a mistake (Laurent and Kapferer, 1985; Kapferer and Laurent, 1993). Depending on the product category, the negative consequences could involve physical, material or psychological aspects. The perceived probability of making a suboptimal decision depends on customer characteristics such as customer experience or the frequency that a customer is exposed to such a decision. A customer who purchases a product category more frequently will gain expertise and experience, reducing the probability of a wrong choice. Therefore, in categories where frequency of purchase is lower, we expect higher loyalty or inertia than in categories where frequency purchase is higher. The frequency of purchase could be considered as a proxy of consumer experience with the product.

Three alternative hypotheses should be proposed to consider these other components of the perceived risk. Therefore, we express $\mathrm{H} 1$ in the following way.

$\mathrm{H}_{1}$ : The higher the category expenditure, the higher SB loyalty will be.

Other considerations imply that:

$\mathrm{H1}_{2}$ : The lower the frequency of purchase in the category, the higher SB loyalty will be.

$\mathrm{H}_{3}$ : The higher the perceived importance of negative consequences in case of poor choice in the category, the higher SB loyalty will be.

\section{Data and variables}

We aimed to study the existence of SB loyalty in household brand choice and to test whether it is different across categories. We analysed brand choice behaviour using discrete-choice models. In particular, we estimated logit models using scanner panel data, supplied by ACNielsen Spain, on household purchases of brands in two product categories: fine laundry detergent and non-fine laundry detergent. The laundry detergent category, without distinguishing between non-fine and fine, has been considered a low-involvement category and a utilitarian product (Laurent and Kapferer, 1985; Sloot et al., 2005). The Spanish dataset includes a representative sample of households across the country, and their purchase activities were recorded from January 1999 to December 2000.

Before testing the proposed hypothesis, we decided on our data and sample selection. We considered households that bought in both categories during the sample period; in this way, we built a complete household panel, ${ }^{1}$ and we estimated logit models using the same variables in both categories. The reason for building a complete panel in terms of households buying in both categories was to avoid differences (similarities) in household buying in just one category. As a result of this sample selection, we have 1095 households accounting for 29459 purchase occasions at 80 stores, comprising 5316 fine laundry detergent purchases and 24143 non-fine laundry detergent purchases. SBs hold 37 percent of the market share in the fine laundry detergent category and 20 percent in non-fine laundry detergent.

Average expenditure by households during the 2 years of purchases of non-fine laundry detergent amounted to $€ 60.30$, while expenditure on fine laundry detergent accounted for $€ 30.62$. There was a significant difference between the expenditure in the two categories. This is the reason for expecting that loyalty or inertia towards SBs in the non-fine laundry detergent category would be higher than for fine-laundry detergent, in accordance with $\mathrm{H} 1_{1}$.

Purchase frequency in the fine laundry detergent category ranged from 1 to 90 , with an average of 14 and a median of eight purchase occasions by households in 2 years. In the non-fine laundry detergent category, the range in purchase frequency ranged from 5 to 187 (the average was 33 and median 27) purchase occasions by each household. We also found there was a significant difference between the mean frequencies in the two categories. This was the reason for expecting that loyalty or inertia towards $\mathrm{SBs}$ in the fine laundry detergent category would be higher than in the nonfine laundry detergent one, in accordance with $\mathrm{H}_{2}$.

The use of both categories by Spanish households is very different, and households use them like complementary goods, not as substitutive goods. The traditional use of the fine laundry detergent is to wash higher quality and more expensive clothes (for example, when package label information recommends the product to wash silk, wool or baby clothes). In this situation, households could consider that the decision to buy fine laundry detergent could have a higher perceived risk than the decision to buy non-fine laundry detergent because the negative consequences in case of poor choice will be higher in the fine laundry detergent category (as suggested by hypothesis $\mathrm{H}_{3}$ ).

To analyse the relative importance of SB loyalty compared to other variables in the model, we include some explanatory variables describing brands and consumers. The variables included in the model specifications are grouped into the following five categories.

\subsection{Price}

"Price ${ }_{i t}^{h}$ " price/weight of brand $i$, at purchase occasion $t$ of household $h$. Weight is equal to $1 \mathrm{~kg}$ and price corresponds to sales price ${ }^{2}$.

\subsection{Socio-demographic variables}

"Size" ${ }^{h}$ " is a count variable ranging from 1 to 5 that represents the size of the household $h$, where value 5 identifies households with five or more members. 
"Social class ${ }^{h}$ " is a dummy variable that takes the value 0 for low-medium class households and 1 for medium-high and high-class households.

"Worker" is a dummy variable, where the value 1 identifies households with a working housewife.

\subsection{Shopping behaviour variable}

"Bigpurchase ${ }^{h}$ " is a dummy variable that takes a value of 1 if the household category expenditure during the period analysed is higher than the average expenditure across all households and 0 otherwise.

\subsection{Loyalty variables}

G\&L (1983) modelled observed past behaviour as:

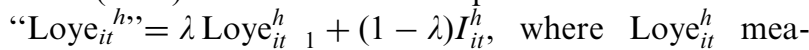
sures loyalty for brand $i$, at purchase occasion $t$ of household $h . I_{i t}^{h}$ is a dummy variable taking a value of 1 if household $h$ bought brand $i$ at purchase occasion $t-1$, and 0 otherwise. Therefore, loyalty is taken to be the exponentially weighted average of past purchases of the brand, treated as $0-1$ variables. To establish brand loyalty, they set Loye $_{i 1}^{h}=\lambda$ if the brand of alternative $i$ was the first purchase in the data history of household $h$, otherwise $(1-\lambda) /($ number of brands -1$)$, thus insuring that the sum of loyalties across brands always equals 1 for any household.

L\&B (1989) used two variables to model observed past behavior:

"Prefer ${ }_{i}^{h}$ ": loyalty of household $h$ to brand $i$, measured by the proportion of purchase occasions in which household $h$ selected brand $i$ during an initialization period. Therefore, this term is constant over time and is designed to capture preference heterogeneity across households.

"Last ${ }_{i t}{ }^{h}$ " is a dummy variable that reflects the relative impact of recent choice behaviour, measured by whether or not household $h$ purchased brand $i$ on occasion $t-1$ (Jones and Landwehr, 1988, variable of purchase-event feedback).

\subsection{Promotional lagged ( $G \& L, 1983 ; L \& B, 1989)$}

"Promo $1_{i t}^{h, "}$ is a dummy variable that reflects the relative impact of previous purchases on promotion. The variable takes a value of 1 if the previous purchase of brand $i$ by household $h$ was a promotional purchase, taking the value of 0 otherwise.

"Promo $2_{i t}^{h}$ " takes a value of 1 if the second previous purchase of brand $i$ by household $h$ was a promotional purchase, taking the value of 0 otherwise.

Table A1 of the Appendix A provides descriptive statistics for the dependent and explanatory variables in the two categories of detergent. When we compared the fine versus the non-fine laundry detergent market, we found that the former had a larger SBs market share and the price gap between SBs and NBs was large. We used the first-year period to initialize the proposed loyalty variables, while the second year was used to estimate the models. Households without information during the initialization period were dropped from the analysis. Following the suggestion of Lattin (1987), we fixed the smoothing constant to build the G\&L loyalty variable ("Loye") at a value of 0.7 . The L\&B loyalty variable ("Prefer") sets the first purchase equal to 0 . "Prefer" was calculated using the initialization purchases.

\section{Model specifications}

We defined the dependent variable of the logit choice model taking into account the SB market share in Spain; therefore, the choice indicator takes a value of 1 when household $h$ at purchase occasion $t$, chose a SB and 0 otherwise for NB. SBs are present in both categories. Two logit models were specified (Model A and Model B) to fix the likelihood that a household $h$ buys an SB in category $c$ (versus buying an NB in that category) on purchase occasion $t(\psi(\mathrm{x})$ is a standard logit cdf $)$ across all stores:

$P_{h c t}^{s b}=\operatorname{Prob}_{h t}(\mathrm{SB}=1$ in category $c)=\psi\left(\mu_{h c t}\right)$

where $\mu_{h c t}$ is the deterministic component of the indirect utility of purchasing the SB relative to the purchase of the NB (i.e., indirect utility of the NB is set to zero). Indirect utility for an SB purchase relative to an NB purchase was specified using a linear additive function.

In Model A, the indirect utility was specified using the G\&L loyalty variable (Loye):

$$
\begin{aligned}
\mu_{h c t}= & \beta_{0}+\beta_{1} \text { Worker }_{h}+\beta_{2} \text { Size }_{h}+\beta_{3} \text { Social-class }_{h} \\
& +\beta_{4} \text { Bigpurchase }_{h}+\beta_{5} \text { Promo }_{h t}+\beta_{6} \text { Promo } 2_{h t} \\
& +\beta_{7} \text { Price }_{h t}+\beta_{8} \text { Loye }_{h t},
\end{aligned}
$$

where $\beta_{0}$ is the variable of SB constant term and the other variables have been described previously.

In Model B, the only change in the indirect utility was the replacement of the G\&L loyalty variable by the two variables used by $L \& B$ that split state dependence (Last) and preferences (Prefer):

$$
\begin{aligned}
\mu_{h c t}= & \beta_{0}+\beta_{1} \text { Worker }_{h}+\beta_{2} \text { Size }_{h}+\beta_{3} \text { Social-class }_{h} \\
& +\beta_{4} \text { Bigpurchase }_{h} \\
& +\beta_{5} \text { Promo }_{h t}+\beta_{6} \text { Promo }_{h t}+\beta_{7} \text { Price }_{h t}+\beta_{8} \text { Prefer }_{h} \\
& +\beta_{9} \text { Last }_{h t},
\end{aligned}
$$

where

$$
\begin{aligned}
\psi\left(\mu_{h c t}\right)= & \left\{\frac{\exp \left(\mu_{h c t}\right)}{1+\exp \left(\mu_{h c t}\right)} \text { if } \mathrm{SB}=1 ;\right. \\
& \left.\frac{1}{1+\exp \left(\mu_{h c t}\right)} \text { if } \mathrm{SB}=0\right\} .
\end{aligned}
$$




\section{Empirical results}

\subsection{Descriptive analysis}

We explored differences in loyalty variables according to brand type (SB versus NB) and product category (fine and non-fine laundry detergent) using cross tabulations (see Table A2 of the Appendix A). Our analysis shows that households that buy SBs are much more likely to repeatpurchase the SB when they have a purchase history of SBs (Loye and Prefer). However, households that bought NBs previously are more likely to repeat-purchase NB (Last). A $\chi^{2}$ test reveals a significant association between brand loyalty and brand type $(p=0.000)$ across detergent categories.

\subsection{Hypothesized effects}

We now estimate and discuss the models previously specified. The estimation results for both categories are detailed in Table A3 of Appendix A. For the purpose of comparing Models A and B, we use different measures of model goodness of fit: the Pseudo- $R^{2}$, and four information criteria suggested by Elrod and Keane (1995). These are the Akaike Information Criterion (AIC), the Hannan and Quinn (HQ), the Bayesian Information Criterion (BIC), and the Consistent Akaike Information Criterion (CAIC). The first measure is defined as Pseudo- $R^{2}=1-\left(\log L / \log L_{C}\right)$, where $\log L$ is the value of the $\log$-likelihood function at the optimum for the complete model, and $\log L_{C}$ is the value of the log-likelihood function at the optimum for a restricted model with only a constant as the explanatory variable. The information criteria are computed as $\mathrm{AIC}=-2 \log L+2 K$, $\mathrm{HQ}=-2 \log L+2 K \ln (\operatorname{Ln}(N)), \quad \mathrm{BIC}=-2 \log L+K \ln (N)$ and CAIC $=-2 \log L+K(\ln (N)+1)$, where $\log L$ is the value of the log-likelihood function for each model, $K$ is the number of parameters estimated, and $N$ is the sample size. We prefer those models with higher values of log-likelihood and Pseudo- $R^{2}$ and smaller values of AIC, HQ, BIC and CAIC. The values of $\log L, K, N$, Pseudo- $R^{2}$, AIC, HQ, BIC and CAIC for each specification and each category are reported below the parameters estimated in Table A3 of the Appendix A. We see from the results that the tests unequivocally favour Model B, which presents higher values of the log-likelihood at the optimum, higher Pseudo- $R^{2}$ and lower values of AIC, HQ, BIC and CAIC than Model A.

In general, the estimated coefficients take the expected signs in both models. Concerning the fine laundry detergent category, the positive sign of the loyalty coefficient implies that loyalty towards SBs increases the probability of purchasing those brands. The state dependence variable reflects the influence of past brand choice on actual brand choice, although this variable is not significant. Promotion-lagged variables do not significantly influence the probability of purchase. The reason could be that there are few promotions in this category. The price has a very significant influence on the purchase of SBs in this category. The coefficient can be interpreted as a quasiprice elasticity. The negative sign implies a substitution effect among SBs and NBs. In both models, the sociodemographic variable of size is significant with a positive sign. Bigger households have higher probability of choosing SBs than do smaller households. The variable social class, which is a proxy for income, has a positive and significant influence on purchasing only in Model B. We can surmise that high and medium social class households use SB. Therefore, SBs are also bought by segments that we suppose are comprised of less price-sensitive consumers. We must, however, be cautious about the result for this variable because it is marginally significant in Model A but becomes non-significant in Model B. It is probably influenced by factors other than income.

In the non-fine laundry detergent category, the positive sign of the loyalty coefficient implies that loyalty towards SBs also increases the probability of purchase of those brands. However, the state dependence variable reflects a significant and negative influence of past brand choice on actual brand choice, which implies some variety-seeking behaviour with respect to the last choice, although the effect is very small. Also in this category, the price coefficient is very significant with the expected negative sign. Promotion has a significant influence, which is negative as we expected (G\&L, 1983). The shopping behaviour variable has a negative coefficient; households with above-average expenditures are less likely to purchase SBs. The intuition behind this finding is straightforward. The SB price format is Every Day Low Price (EDLP); therefore, expenditure on non-fine laundry detergent for SB shoppers will be lower than for NB shoppers. On the other hand, households with working housewives have a greater probability of buying SBs. Employment status in the household is related to search costs. Households with a working housewife have less time for shopping, so it seems that SBs could be a choice that allows reducing search costs. Household size is not significant in this category. Social class is significant with a positive sign in Model A, but this result is not consistent in Model B. Thus, the same comment made above also applies here.

Estimated coefficients from discrete-choice models provide relevant qualitative, but not complete, information on when we may expect to compute the effect of any explanatory variable on brand choice decisions. The reason is that we are interested in the effects on the probability of observing the event but we are not normally interested in the effects on the latent variable that the coefficients directly collect. So, we present marginal effects, i.e., changes in the probability due to marginal changes in the explanatory variables (Greene, 2003). We could use these marginal loyalty effects to validate our proposed hypothesis (Sloot et al., 2005). The effects for loyalty are shown in Table 1.

In Model A, loyalty increases on "Loye" have positive effects on the probability of substituting NBs for SBs in 


\begin{tabular}{|c|c|c|c|c|}
\hline Variables & \multicolumn{2}{|c|}{ Model A; using G\&L loyalty variable } & \multicolumn{2}{|c|}{ Model B; using L\&B loyalty variables } \\
\hline Loye & $0.17(0.04)$ & $0.06(0.01)$ & & \\
\hline Prefer & & & $0.10(0.03)$ & $0.05(0.01)$ \\
\hline Last & & & $0.01(0.02)$ & $0.01(0.002)$ \\
\hline
\end{tabular}

Notes: 1 . Table entries are mean marginal effects, with standard deviation (in parentheses).

both categories. Regarding hypothesis H1, we observe that the effect on the probability of choosing SBs when there is an infinitesimal change in loyalty is greater for fine laundry detergent than for non-fine laundry detergent. As a result, we cannot reject $\mathrm{H}_{2}$ or $\mathrm{H}_{3}$ and, therefore, we reject $\mathrm{H} 1_{1}$. In Model B, an increase in preference "Prefer" implies a positive effect on the probability of choosing SBs in the future for both categories of detergent. In accordance with this finding, in Model B we observe that the effect on the probability of choosing SBs when there is an infinitesimal change in loyalty is higher for fine laundry detergent than for non-fine laundry detergent. Thus, we cannot reject $\mathrm{H}_{2}$ or $\mathrm{H}_{3}$, and, therefore, we reject $\mathrm{H}_{1}$. However, the loyalty effect is split between two variables in Model B: brand preferences "prefer" and state dependence "Last". State dependence reflects the influence of past brand choice on actual brand choice. This variable is not significant in fine laundry detergent, although it is significant in non-fine laundry detergent, although with a small negative effect. The negative sign implies some variety seeking with respect to the last choice made in this category.

\section{Conclusions and implications}

In this study, we examined the existence of store brand loyalty in the behaviour of Spanish consumers in the purchase of laundry detergent. This result could partially explain the increase in store brands' market share generated by repetitive choice behaviour; namely, once households try store brands, a large proportion of them continue buying on subsequent purchase occasions. Our results suggest that store brands are getting behavioural loyalty. In the Spanish case particularly, store brands present an important repetitive brand choice behaviour that in global terms is greater than behavioural loyalty to national brands. Therefore, our results support the insight of Erdem et al. (2004) that store brands can build brand equity. Our study's focus is on brand behavioural loyalty as a foundation of brand equity.

Furthermore, we have tried in this paper to answer whether store brand loyalty is different across categories (fine laundry detergent versus non-fine laundry detergent). In attempting to explain these across-category variations, we considered the effect of perceived risk on brand choice.
The empirical results show that the degree of store brand loyalty differs across categories. Thus, we concluded that loyalty is a consumer behaviour that varies across categories and across store brands. The results seems to imply that the perceived importance of negative consequences in case of poor choice and the perceived probability of making such a mistake have more influence on perceived risk than the financial aspect of the risk represented by incurring higher average category expenditure. However, Batra and Sinha (2000) demonstrated opposite results; that is, that brand share is higher in categories with low perceived consumer risk. One limitation of that study is that data come from a survey rather than scanner data, so repetitive choice behaviour cannot be studied. Our study considers the dynamic choice process and our results show that after trying store brands in the category, a way to reduce the perceived importance of negative consequences in the case of poor choice and reducing the perceived probability of making such a mistake is to keep buying the same store brands where they have had good results.

We explain our different results as a consequence of store brand loyalty, trying store brands, and having good experiences. Because of good quality and lower quality variability of store brands in Spain (Erdem et al., 2004; Medina et al., 2004), the consumer keeps purchasing the store brands, and he/she uses loyalty to reduce the risk of making a mistake in the purchase of store brands. Therefore, financial risk does not seem to be the only determinant for choosing store brands in some categories.

From our results, we can suggest some implications for retailers.

If retailers use store brands and obtain loyalty towards them, then the retailers will enjoy the advantages of brand loyalty. Brand loyalty leads to certain marketing advantages, such as reducing marketing costs, generating more new customers, giving greater trade leverage, increasing market share and relative price, reducing search motivation, providing favourable word of mouth, and generating greater resistance of loyal customers toward competitive strategies (Aaker, 1991; Dick and Basu, 1994; Chaudhuri and Holbrook, 2001).

For retailers, store customer loyalty is also a fundamental reason for having their own labels. In categories where store brand loyalty is higher, the store brands will 
have a strong position in the category and can be used as a marketing tool to attract customers to buy at the store, thus building store customer loyalty. Store brands can be used to increase store loyalty and to differentiate the store from other retailers. Households may possess intrinsic brand loyalty towards store brands. This is consistent with the idea that customers switch stores primarily to purchase their preferred brands. If the preferred brand is a store brand, then the household will buy in that store, building store loyalty. Recent empirical findings indeed connect store brand use and store loyalty (Corstjens and Lal, 2000; Ailawadi et al., 2001).

Therefore, success of store brands is an important factor in building a retailer's brand equity. Store brand loyalty and store loyalty seem importants dimensions of building a retailer's brand equity. In the case that households are loyal to store brands that are cheaper than manufacturers' brands and buy from the retailer, the retailer could have a "resource premium", i.e., households are willing to spend in order to shop with the retailer (Ailawadi and Keller, 2004).

Retailers with successful store brands well may think about their strategic decision to hold a store brand portfolio. Store brands sell at a lower price than national brands with good quality levels, so the retailer could launch different store brands positioned with different prices aimed at different customer segments-for example, premium quality, high value-added store brands that are not priced lower than national brands targeting less pricesensitive consumers. Using this strategy, the retailers could increase their retail margin, increase retailer loyalty and also strengthen the retailer's negotiating position vis-à-vis manufacturers.

Consumers worry about the perceived importance of negative consequences in the case of poor choice and the perceived probability of making such a mistake when they buy store brands. Retailers, to reduce these components of risk, need to put as much objective information about product ingredients and manufacturing quality as possible on the package label, to reduce the uncertainty the consumer feels about the quality of store brands. Also, the retailer should attempt to induce the consumer to test store brands, for example, with free samples, to allow the consumer to have experience of store brands, because after trying the store brands the consumer seems to keep purchasing them.

Finally, we find signs of unobservable household heterogeneity, i.e., very significant store brand constant terms in the model. In future research, we may be able to improve model performance by controlling for unobservable heterogeneity (Keane, 1997; Ailawadi et al., 1999). Subject to data availability, the analysis could be repeated across more than two categories, in packed consumer goods and non-packed consumer goods. Survey research could be conducted to investigate attitudinal store brand loyalty, consumer involvement and consumer-perceived risk.

Notes:

1. If we do not consider households buying both categories, the differences or similarities in results could indicate behavioural differences or similarities provided by households that only buy one category.

2. We only have shelf prices from the bought brands. The information about features and displays is not available; nor do we have data about size discounts in the cases of price promotion.

\section{Acknowledgements}

We would like to thank ACNielsen Spain for providing the scanner panel data used in this paper. This research was supported by Ministerio de Educación y Ciencia Dir. Gral de Investigación, Grant SEJ2004-00672.

\section{Appendix A}

Tables A1-A3.

Table A1

Descriptive statistics

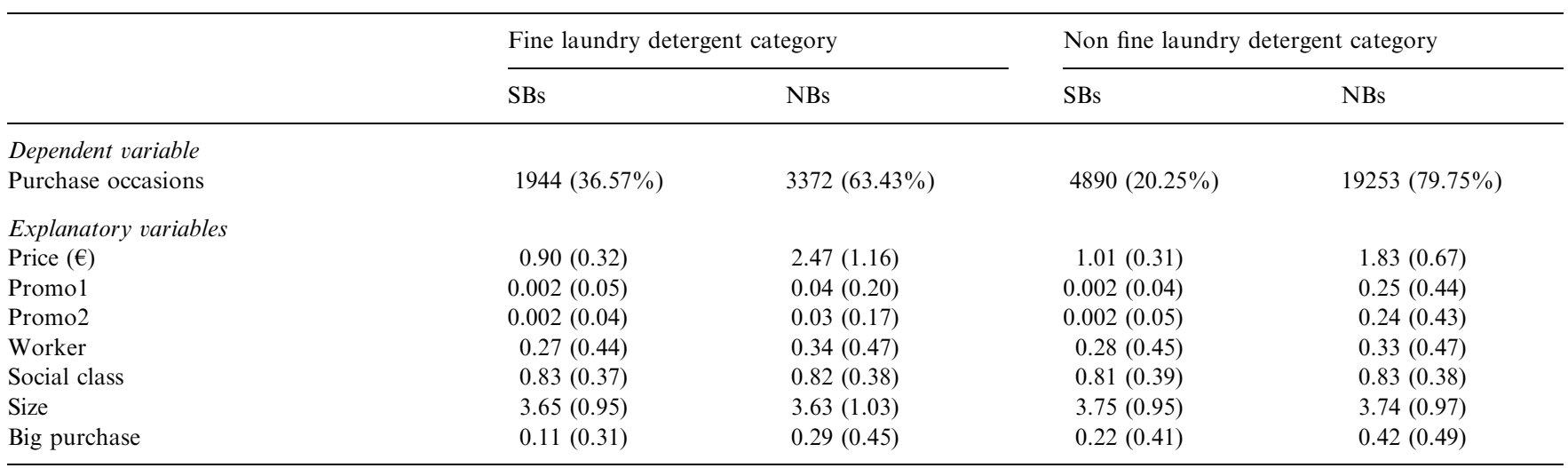

Notes: (1) Store brands (SBs) and national brands (NBs); (2) Table entries are, mean value, with standard deviation (in parentheses). 
Table A2

Descriptive statistics and ANOVA of loyalty variables

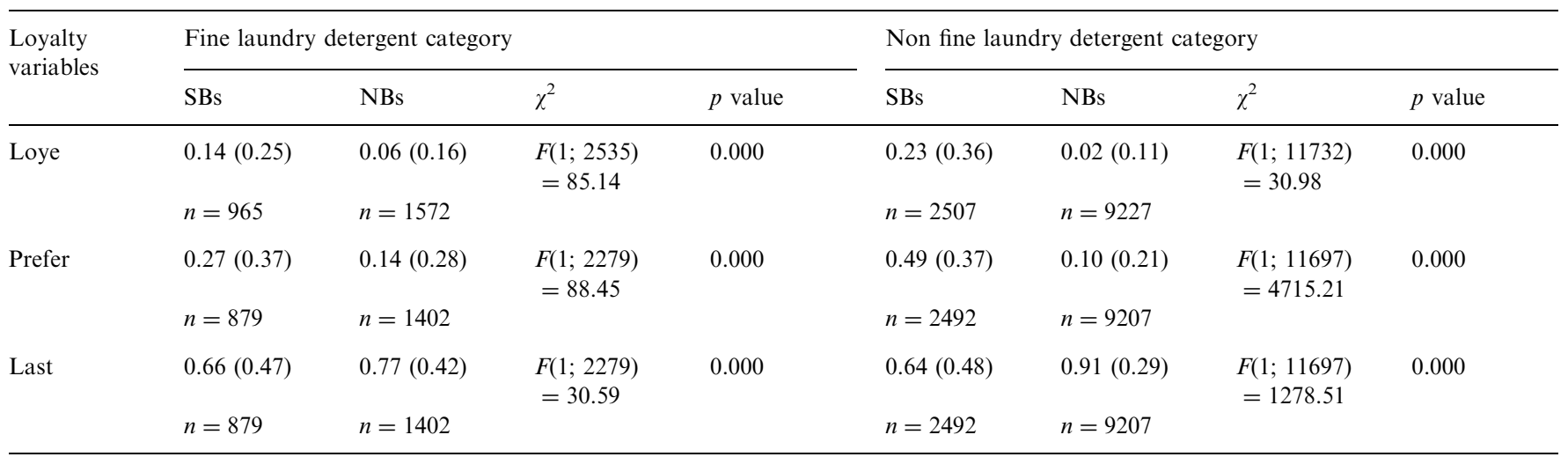

Notes: (1) Store brands (SBs) and national brands (NBs); (2) Table entries are, in the first line, mean value with standard deviation (in parentheses), followed by number of purchase occasions in the below line; (3) $p$ value from a two tailed $t$ test.

Table A3

Estimation results

\begin{tabular}{|c|c|c|c|c|}
\hline & \multicolumn{2}{|c|}{ Model A, using G\&L loyalty variable } & \multicolumn{2}{|c|}{ Model B, using L\&B loyalty variables } \\
\hline & $\begin{array}{l}\text { Fine laundry detergent } \\
\text { category }\end{array}$ & $\begin{array}{l}\text { Non fine laundry } \\
\text { detergent category }\end{array}$ & $\begin{array}{l}\text { Fine laundry detergent } \\
\text { category }\end{array}$ & $\begin{array}{l}\text { Non fine laundry } \\
\text { detergent category }\end{array}$ \\
\hline \multicolumn{5}{|l|}{ Variables } \\
\hline Loye & $1.59(0.33)$ & $3.14(0.16)$ & & \\
\hline Prefer & & & $0.93(0.25)$ & $2.96(0.12)$ \\
\hline Last & & & $0.10(0.18)$ & $0.28(0.09)$ \\
\hline Promo2 & $1.13(0.82)$ & $3.46(0.31)$ & $1.39(0.85)$ & $3.43(0.32)$ \\
\hline Price & $3.36(0.14)$ & $3.13(0.08)$ & $3.45(0.15)$ & $3.07(0.09)$ \\
\hline Social Class & $0.38(0.18)$ & $0.29(0.09)$ & $0.25(0.20)$ & $0.10(0.09)$ \\
\hline Worker & $0.16(0.16)$ & $0.14(0.08)$ & $0.06(0.17)$ & $0.25(0.08)$ \\
\hline Big purchase & $0.15(0.20)$ & $0.68(0.08)$ & $0.05(0.20)$ & $0.63(0.08)$ \\
\hline Size & $0.20(0.07)$ & $0.01(0.04)$ & $0.25(0.08)$ & $0.01(0.04)$ \\
\hline Constant & $3.06(0.33)$ & $3.15(0.19)$ & $3.19(0.38)$ & $2.87(0.21)$ \\
\hline Pseudo $R^{2}$ & 0.5811 & 0.5341 & 0.5969 & 0.5707 \\
\hline AIC & 1430 & 5690 & 1244 & 5222 \\
\hline HQ & 1449 & 5712 & 1265 & 5247 \\
\hline $\mathrm{BIC}$ & 1483 & 5756 & 1301 & 5296 \\
\hline CAIC & 1492 & 5765 & 1311 & 5306 \\
\hline
\end{tabular}

Notes: (1) Table entries are: value coefficient, with standard deviation (in parentheses); (2) Pseudo $R^{2}=1 \quad\left(\log L / \log L_{C}\right.$ ), where $\log L$ is the value of the $\log$ likelihood function at the optimum for the complete model and $\log L_{C}$ is the value of the $\log$ likelihood function at the optimum for a restricted model with only a constant as the explanatory variable; (3) Akaike Information Criterion (AIC $=2 \log L+2 K$ ); Hannan and Quinn $(\mathrm{HQ}=2 \log L+2 K \ln (\operatorname{Ln}(N))$; Bayesian Information Criterion $(\mathrm{BIC}=2 \log L+K \ln (N))$; and Consistent Akaike Information Criterion $(\mathrm{CAIC}=2 \log L+K(\ln (N)+1))$. Here, $\log L$ is the value of the $\log$ likelihood function for each model, $K$ is the number of parameters estimated, and $N$ is the sample size.

\section{References}

Aaker, D., 1991. Managing Brand Equity: Capitalizing on the Value of a Brand Name. The Free Press, New York.

ACNielsen, 2005. The power of private label.

Ailawadi, K., Keller, K., 2004. Understanding retail branding: conceptual insights and research priorities. Journal of Retailing 80, 331342.

Ailawadi, K., Gedenk, K., Neslin, S., 1999. Heterogeneity and purchase event feedback in choice models: an empirical analysis with implica tions for model building. International Journal of Research in Marketing 16, 177198.

Ailawadi, K., Neslin, S., Gedenk, K., 2001. Pursuing the value conscious consumers: store brands versus national brand promotions. Journal of Marketing 65, 7189 .

Assael, H., 1998. Consumer Behavior and Marketing Action. South Western College Publishing, Cincinnati.

Batra, R., Sinha, I., 2000. Consumer level factors moderating the success of private label brands. Journal of Retailing 76 (2), 175191. 
Bronnenberg, B.J., Wathieu, L., 1996. Asymmetric promotion effects and brand positioning. Marketing Science 15 (4), 379394.

Burton, S., Lichtenstein, D., Netemeyer, R., Garretson, J., 1998. A scale for measuring attitude toward private label products and an examination of its psychological and behavioral correlates. Journal of the Academy of Marketing Science 26 (4), 293306.

Chaudhuri, A., Holbrook, M., 2001. the chain of effects from brand trust and brand affect to brand performance: the role of brand loyalty. Journal of Marketing 65 (April), 8193.

Corstjens, M., Lal, R., 2000. Building store loyalty through store brands. Journal of Marketing Research 37 (3), 281291.

Dhar, S., Hoch, J., 1997. Why store brand penetration varies by retailer. Marketing Science 16 (3), 208227.

Dick, A., Basu, K., 1994. Customer loyalty: toward an integrated conceptual framework. Journal of the Academy of Marketing Science $22(2), 99113$.

Elrod, T., Keane, M.P., 1995. A factor analytic probit model for representing the market structure in panel data. Journal of Marketing Research 32 (1), 116.

Erdem, T., 1996. A dynamic analysis of market structure using panel data. Marketing Science 15 (4), 359378.

Erdem, T., Zhao, Y., Valenzuela, A., 2004. Performance of store brands: a cross country analysis of consumer store brand preferences, percep tions, and risk. Journal of Marketing Research 41 (1), 86100.

Fader, P., Lattin, J., 1993. Accounting for heterogeneity and nonstatio narity in a cross sectional model of consumer purchase behavior. Marketing Science 12 (3), 304317.

Garretson, J., Fisher, D., Burton, S., 2002. Antecedents of private label attitude and national brand promotion attitude: similarities and differences. Journal of Retailing 78, 9199.

Gónzalez, C., Díaz, A.M., Trespalaciones, J.A., 2006. Antecedents of the difference in perceived risk between store brands and national brands. European Journal of Marketing 40 (1/2), 6182.

Greene, W., 2003. Econometric Analysis, fifth ed. Prentice Hall, Upper Saddle River, NJ.

Guadagni, P., Little, J., 1983. A logit model of brand choice calibrated on scanner data. Marketing Science 2 (3), 203238.

Howard, J., Sheth, J., 1969. The Theory of Buyer Behavior. Wiley, New York.

Jones, M., Landwehr, J., 1988. Removing heterogeneity bias from logit model estimation. Marketing Science 7 (Winter), 4159.

Juhl, H.J., Esbjerg, L., Grunert, K.G., Bech Larsen, T., Brunso, K., 2006. The fight between store brands and national brands what's the score? Journal of Retailing and Consumer Services 13 (September), 331338.

Kahn, B., Kalwani, M., Morrison, D., 1986. Measuring variety seeking and reinforcement behaviors using panel data. Journal of Marketing Research 23 (May), 89100.

Kapferer, J N., Laurent, G., 1993. Further evidence on the consumer involvement profile: five antecedents of involvement. Psychology and Marketing 10 (4), 347355.
Keane, M., 1997. Modeling heterogeneity and state dependence in consumer choice behavior. Journal of Business and Economic Statistics 15 (3), 310327.

Keller, K., 2003. Strategic Brand Management: Building, Measuring and Managing Brand Equity. Prentice Hall, Upper Saddle River, NJ.

Kim, J., Allenby, G., Rossi, P., 2002. Modeling consumer demand for variety. Marketing Science 21 (Summer), 229250.

Lattin, J., 1987. A model of balanced choice behavior. Marketing Science 6 (Winter), 4865.

Lattin, J., Bucklin, R., 1989. Reference effects of price and promotion on brand choice behavior. Journal of Marketing Research 26 (August), 299310.

Laurent, G., Kapferer, J. N., 1985. Measuring consumer involvement profiles. Journal of Marketing Research 12 (February), 4153.

Marketing Letters, 1999. Special Issue on Choice Modelling 10 (3).

Marketing Letters, 2002. Special Issue on Choice Modelling 10 (3).

Marketing Letters, 2005. In: Special Issue on the Proceedings of the Sixth Invitational Choice Symposium, vol. 16(3/4).

Medina, O., Méndez, J.L., Rubio, N., 2004. Price quality and market share of consumer goods in Spain: retail brands and manufacturer brands. International Review of Retail, Distribution and Consumer Research 4 (2), 199222.

McAlister, L., 1982. A dynamic attribute satiation model for choices made across time. Journal of Consumer Research 9 (September), 141150.

McFadden, D., 1973. Conditional logit analysis of qualitative choice behavior. In: Zarembka, P. (Ed.), Frontiers in Econometrics. Academic Press, New York, pp. 105142 (Chapter 4).

Ortmeyer, G., Lattin, J., Montgomery, D., 1991. Individual differences in response to consumer promotions. International Journal of Research in Marketing 8, 169186.

Richardson, P., Jain, A., Dick, A., 1996. Household store brand proneness: a framework. Journal of Retailing 72 (2), 159185.

Roselius, T., 1971. Consumer rankings of risk reduction methods. Journal of Marketing 35 (January), 5661.

Seetharaman, P., Ainslie, A., Chintagunta, P., 1999. Investigating house hold state dependence effects across categories. Journal of Marketing Research 36 (November), 488500.

Sheth, J., Venkatesan, M., 1968. Risk reduction processes in repetitive consumer behavior. Journal of Marketing Research 5, 307310.

Sloot, L., Verhoef, P., Franses, P., 2005. The impact of brand equity and the hedonic level of products on consumer stock out reactions. Journal of Retailing 81 (1), 1534.

Steenkamp, J. B., Dekimpe, M., 1997. The increasing power of store brands: building loyalty and market share. Long Range Planning 30 (6), 917930 .

Wulf, K., Odekerken Schroder, G., Goedertier, F., Van Ossell, G., 2005. Consumer perceptions of store brands versus national brands. Journal of Consumer Marketing 22 (4), 223232. 